\title{
Theoretical Study on Prestress Loss in Cross-Tensioned Concrete Pavement with BFRP Tendons
}

\author{
Yating Zhang ${ }^{1, *}$ and Zhiyi Huang ${ }^{2}$ \\ 1 School of Environmental and Civil Engineering, Jiangnan University, Wuxi 214122, China \\ 2 College of Civil Engineering and Architecture, Zhejiang University, Hangzhou 310058, China; hzy@zju.edu.cn \\ * Correspondence: ytzhang@jiangnan.edu.cn; Tel.: +86-0510-8591-2822
}

Received: 3 October 2020; Accepted: 30 October 2020; Published: 31 October 2020

\begin{abstract}
Cross-tensioned concrete pavement can reduce transverse joints and cracks and improve the durability of the pavement, and the decrease in slab thickness can be achieved without damaging the performance of the pavement. However, the corrosion of the steel can cause serious damage to the pavement structure, resulting in higher maintenance costs and shorter service life. Basalt fiber-reinforced polymer (BFRP) has been proven to be an effective alternative in both jointed plain concrete pavement (JPCP) and continuously reinforced concrete pavement (CRCP) due to its lightweight and corrosion-resistant properties. In this paper, a systematic theoretical method for determining the prestress loss of BFRP tendons in cross-tensioned concrete pavement was proposed, with the impact of the slab width and distribution angle of the prestressed tendon on the prestress loss being studied and compared to the results of traditional steel strands. Results showed that the proportion of the prestress loss due to anchorage deformation and prestress retraction in the prestressing stage rose with the increase in distribution angle and the decrease in slab width, while the prestress loss during the in-service stage was a constant value for both BFRP tendons and steel strands. The prestress loss of BFRP tendons was far lower than that of steel strands in both prestressing stage and in-service stage for a given slab width $(3 \mathrm{~m}, 4.5 \mathrm{~m}, 9.0 \mathrm{~m}, 12.75 \mathrm{~m})$ and distribution angle $\left(20^{\circ}, 25^{\circ}\right.$, $\left.30^{\circ}, 35^{\circ}, 40^{\circ}, 45^{\circ}\right)$, and the difference ranged from $6.4 \%$ to $16 \%$, signifying the feasibility of BFRP tendons in cross-tensioned concrete pavement. Overall, the smaller the slab width, the greater the difference of the prestress loss between BFRP tendons and steel strands.
\end{abstract}

Keywords: cross-tensioned concrete pavement; basalt fiber-reinforced polymer (BFRP); prestress loss; steel strands; distribution angle; slab width

\section{Introduction}

Transverse joints in jointed plain concrete pavement (JPCP) can lead to several distresses, i.e., pumping, spalling, corner breaks, and even faulting, if they are not treated appropriately. Cross-tensioned concrete pavement has been proposed as an effective solution in enhancing the crack resistance of concrete pavement in order to improve the durability of concrete pavement and reduce the number of transverse joints.

Pre-compression stress can be produced in the concrete slab by imposing an external tensioning to the reinforcement tendon, counteracting the flexural and tensile stress caused by the traffic load and environmental factors; as a result, the crack resistance and durability of the concrete pavement can be significantly improved [1,2]. Merritt et al. [3,4] demonstrated the thickness and prestress requirements of prestressed concrete pavement by launching a precast prestressed concrete pavement pilot project near Georgetown, Texas. Currently, researchers [5-10] have carried out many studies on the design, construction, and structural analysis under vehicle load and thermal gradient of the prestressed concrete pavement given both theoretical and numerical methods, but without giving 
much consideration on the prestress loss, which is an important factor and cannot be neglected in the design of the cross-tensioned concrete pavement.

The concrete panel will continue to bear a high-level pre-compression stress with the overestimated prestress loss, resulting in excessive invert arch, which not only undermines the performance of the pavement structure but also causes the waste of materials [11]. On the contrary, if the estimated prestress loss is lower than the actual value, it will lead to insufficient pre-compression stress in the pavement slab, causing premature cracking of the slab and failure to achieve the desired effect of prestressed pavement [12]. Therefore, an accurate estimation of the prestress loss of prestressed tendons is necessary to ensure the performance and durability of the prestressed concrete pavement. $\mathrm{Au}$ and Si [13] proposed a new relaxation model for steel strands that was based on the equivalent creep coefficient to provide accurate time-dependent prestress loss of cable forces. Kim et al. [14] evaluated the friction coefficients between the strand and the duct with smart strands on the basis of a full-scale test specimen and two actual long-span girder bridges. Yang et al. [15] developed a refined method for the calculation of time-dependent prestress losses in prestressed concrete girders and verified the proposed method with numerical results. However, the existing studies on prestress loss are mainly for bridges and beams, and mostly involve steel strands.

Despite the decreased transverse cracks in cross-tensioned concrete pavement, the corrosion of the steel can still cause great damage to the performance and durability of the prestressed pavement structure, resulting in high maintenance costs $[16,17]$. Recently, new materials such as basalt fiber-reinforced polymer (BFRP), which is lightweight and corrosion-resistant [18], has been widely used as longitudinal reinforcement in continuously reinforced concrete pavement (CRCP), and has been proven to be a promising alternative to steel in CRCP given excellent bond relationship between the BFRP and the concrete $[19,20]$. Nonetheless, no study has been found in the literature regarding the application of the BFRP in cross-tensioned concrete pavement. Due to the difference in the relaxation mechanism of fiber-reinforced tendons and steel strands, the traditional method for calculating the prestress loss of steel strands cannot be directly used for calculating the prestress loss of BFRP tendons in cross-tensioned concrete pavements.

In this paper, a systematic theoretical method was proposed for calculating the prestress loss of BFRP tendons in cross-tensioned concrete pavement. The effect of the concrete slab width and distribution angle of the BFRP tendons on prestress loss was discussed using the proposed method. Given various slab width and distribution angles of the prestressed tendon, the prestress loss of BFRP tendons was then compared to that of the steel strands in order to demonstrate the feasibility of the BFRP tendon in cross-tensioned concrete pavement.

\section{Theoretical Method for Determining Prestress Loss of BFRP Tendons}

Generally, the prestress loss in cross-tensioned concrete pavements arise from five causes [21], namely, the loss caused by anchorage deformation and prestress retraction $\left(\sigma_{11}\right)$, the loss caused due to the friction between prestressed tendons and their surrounding casing pipes $\left(\sigma_{12}\right)$, the loss caused because of the elastic compression of concrete $\left(\sigma_{13}\right)$, the loss resulted from the relaxation of prestress tendons $\left(\sigma_{14}\right)$, and the loss arising from concrete shrinkage and concrete creep $\left(\sigma_{15}\right)$.

\subsection{Prestress Loss Due to Anchorage Deformation and Prestress Retraction}

After the BFRP tendons are stretched, relative displacement is produced due to the deformation of the anchor and the base plate as well as the retraction of the BFRP tendons, and as a result, the prestress loss caused by anchorage deformation and prestress retraction $\sigma_{11}$ occurs around the anchorage area and can be calculated with Equation (1).

$$
\sigma_{l 1}=\frac{a}{l} E_{\mathrm{fp}}
$$

where $a$ is the length of the anchorage deformation and prestress retraction of BFRP tendons, $l$ is the distance between the tension end and the anchor end, and $E_{\mathrm{fp}}$ is the elastic modulus of BFRP tendons. 


\subsection{Prestress Loss from the Friction between BFRP Tendons and the Surrounding Casing Pipe}

BFRP tendons deflect under their own weight, resulting in friction between the prestressed BFRP tendons and the casing wall during tensioning. The friction is related to the length of the prestressed BFRP tendons, given the fact that the longer the length of the prestressed BFRP tendons, the higher the friction, and therefore the higher the prestress loss caused due to the friction, which can be obtained through Equation (2).

$$
\sigma_{l 2}=\sigma_{\mathrm{con}}\left(1-\frac{1}{e^{\kappa x+\mu \theta}}\right)
$$

where $\sigma_{\text {con }}$ is the tension control stress of the prestressed BFRP tendon, $\kappa$ is the coefficient of the casing pipe, $\mu$ is the friction coefficient between the BFRP tendon and the casing wall, $x$ is the distance between the calculation cross-section and the anchor end, and $\theta$ is the tangent angle between the calculation cross-section and the anchor end.

\subsection{Prestress Loss Due to Elastic Compression of Concrete}

Hypertension was adopted in cross-tensioned concrete pavements, and therefore the elastic compression loss arising from the batched tension process can be greatly reduced. As a result, the prestress loss caused by the elastic compression of concrete can be neglected in prestressed BFRP concrete pavements [22].

\subsection{Prestress Loss from the Relaxation of Prestress Tendons}

For BFRP tendons, plastic deformation appears with time under high stress or constant tensile stress. Therefore, the stress in BFRP tendons reduces with time, given the unchanged length of BFRP tendons, resulting in the relaxation of BFRP tendons. In addition, the deformation of BFRP tendons also increases with time if the stress of BFRP tendons keeps the same, which is the creep of BFRP tendons. For cross-tensioned concrete pavements, both the relaxation and the creep of BFRP tendons can give rise to the prestress loss [23,24], as shown in Equation (3).

$$
\sigma_{l 4}=r \sigma_{\mathrm{con}}
$$

where $r$ is the relaxation loss rate. The prestress loss resulted from the relaxation of BFRP tendons can be calculated with Equation (4) on the basis of the relaxation mechanism of BFRP tendons.

$$
\sigma_{l 4}=\sigma_{1}+\sigma_{2}+\sigma_{3}
$$

where $\sigma_{1}$ is the prestress loss arising from the creep of the BFRP tendon, and can be obtained with Equation (5); $\sigma_{2}$ is the prestress loss caused by fiber straightening, relating to the pultrusion process of the BFRP tendon, being around $0.01 \sigma_{\mathrm{con}}$ to $0.02 \sigma_{\mathrm{con}}$; and $\sigma_{3}$ is the loss resulted from the relaxation of the prestressed fiber-reinforced polymer tendon itself and is related to the type of the fiber.

$$
\sigma_{1}=\frac{v_{\mathrm{r}} \sigma_{\mathrm{con}} E_{\mathrm{r}}}{E_{\mathrm{f}}}
$$

where $v_{\mathrm{r}}$ is the volume content of the resin in BFRP tendons, and $E_{\mathrm{r}} / E_{\mathrm{f}}$ is the ratio of the elastic modulus of resin to the elastic modulus of filament of BFRP tendons.

\subsection{Prestress Loss Due to Concrete Shrinkage and Creep}

The concrete shrinkage refers to the volume change caused by concrete hardening and it has nothing to do with the load on the pavement structure, while the concrete creep refers to the phenomenon that the strain or deformation of the concrete structure increases with time when the structure is subjected to a long-term load. Both of the concrete shrinkage and concrete creep result in the increase in concrete deformation, which causes redistribution of stress in the reinforced concrete section, and therefore the 
prestress loss is produced. The calculation of the prestress loss caused due to concrete shrinkage and creep is defined in Equation (6) [25].

$$
\sigma_{l 5}=\frac{55+300 \frac{\sigma_{\mathrm{pc}}}{f^{\prime} \mathrm{cu}}}{1+15 \rho} \cdot \frac{E_{\mathrm{fp}}}{E_{\mathrm{p}}}
$$

where $\sigma_{\mathrm{pc}}$ is the normal compressive stress of the concrete at the resultant point of prestressed tendons; $E_{\mathrm{fp}}$ and $E_{\mathrm{p}}$ are the elastic modulus of the prestressed BFRP tendons and the steel strands, respectively; $f^{\prime}{ }_{\text {cu }}$ is the compressive strength of the concrete; and $\rho$ is the reinforcement ratio of BFRP tendons.

Given a specific physical project, material properties of the pre-stressed BFRP tendons and design parameters of the cross-tensioned pavement can be obtained, and therefore the corresponding pre-stress loss of BFRP tendons can be calculated with the proposed methods, as shown in Equations (1)-(6). With the accurate predicted pre-stress loss, an appropriate design of BFRP tendons can be achieved to avoid both excessive and insufficient pre-stress, which can result in invert arch and premature cracking in cross-tensioned concrete pavement, respectively.

\section{Theoretical Analysis of Prestress Loss of BFRP Tendons}

\subsection{Input Parameters}

The width of the cross-tensioned concrete pavement was assumed to be $3.0 \mathrm{~m}, 4.5 \mathrm{~m}, 9.0 \mathrm{~m}$, and $12.75 \mathrm{~m}$, with a thickness of $0.2 \mathrm{~m}$. The elastic modulus of concrete was assumed to be $30 \mathrm{GPa}$. The diameter of the BFRP tendon was assumed to be $16 \mathrm{~mm}$, and the corresponding nominal cross-sectional area was $201 \mathrm{~mm}^{2}$. The ultimate tensile strength and elastic modulus were assumed to be $1300 \mathrm{MPa}$ and $40 \mathrm{GPa}$, respectively, according to previous study [26].

A total of six distribution angles from $20^{\circ}$ to $45^{\circ}$ with an interval of $5^{\circ}$ were selected for BFRP tendons. The tension control stress of the BFRP tendon was assumed to be $65 \%$ of the ultimate tensile strength, namely, $845 \mathrm{MPa}$ in this case. In order to determine the spacing of the BFRP tendon at different distribution angles, the mean longitudinal compressive stress given the distribution angle and the spacing of $30^{\circ}$ and $1000 \mathrm{~mm}$ was calculated by using Equation (7).

$$
\sigma_{\mathrm{py}}=\frac{2\left(\sigma_{\mathrm{con}}-\sigma_{l}\right) \times A_{\mathrm{p}} \times \cos \alpha}{h \times l \times \tan \alpha}
$$

where $\sigma_{\mathrm{py}}$ is the mean longitudinal compressive stress, $\sigma_{l}$ is the total prestress loss, $A_{\mathrm{p}}$ is the nominal sectional area of the prestressed tendons, $h$ is the thickness of the concrete slab, $l$ is the longitudinal distance of the prestressed tendons, and $\alpha$ is the distribution angle of the prestressed tendons. Correspondingly, the mean longitudinal compressive stress of $2.55 \mathrm{MPa}$ was obtained for BFRP tendons. On the basis of the mean longitudinal compressive stress, the spacing of BFRP tendons for each distribution angle $\left(20^{\circ}, 25^{\circ}, 30^{\circ}, 35^{\circ}, 40^{\circ}\right.$, and $\left.45^{\circ}\right)$ can be calculated, as summarized in Table 1 , indicating that the greater the distribution angle of BFRP tendons, the less spacing there was between BFRP tendons.

Table 1. The spacing of basalt fiber-reinforced polymer (BFRP) tendons at different distribution angles (mm).

\begin{tabular}{cc}
\hline Distribution Angle $\left(^{\circ}\right)$ & Spacing of BFRP Tendons (mm) \\
\hline 20 & 1720 \\
25 & 1295 \\
30 & 1000 \\
35 & 779 \\
40 & 608 \\
45 & 471 \\
\hline
\end{tabular}




\subsection{Results and Discussions}

On the basis of the appearance time, the prestress loss can be classified into two stages, i.e., prestressing stage and in-service stage, given that the losses in prestressing stage and in-service stage are instantaneous losses and time-dependent losses, respectively [27]. In general, the prestress loss caused by anchorage deformation and prestress retraction $\left(\sigma_{11}\right)$, friction between prestressed tendons and their surrounding casing pipes $\left(\sigma_{12}\right)$, and elastic compression of concrete $\left(\sigma_{13}\right)$ is produced in the prestressing stage. The prestress loss caused by the relaxation of prestressed tendons $\left(\sigma_{14}\right)$, and concrete shrinkage and concrete creep $\left(\sigma_{15}\right)$ is produced in the in-service stage, usually lasting for a long period.

\subsubsection{Prestress Loss in the Prestressing Stage}

The prestress loss of BFRP tendons with different distribution angles $\left(20^{\circ}, 25^{\circ}, 30^{\circ}, 35^{\circ}, 40^{\circ}\right.$, and $\left.45^{\circ}\right)$ in the prestressing stage given the slab width of $3.0 \mathrm{~m}, 4.5 \mathrm{~m}, 9.0 \mathrm{~m}$, and $12.75 \mathrm{~m}$ are summarized in Tables $2-5$, respectively.

Table 2. Theoretical prestress loss of BFRP tendons given the slab width of $3.0 \mathrm{~m}$.

\begin{tabular}{|c|c|c|c|c|c|}
\hline \multirow{2}{*}{ Distribution Angle $\left({ }^{\circ}\right)$} & \multirow{2}{*}{ Length of BFRP Tendon (mm) } & \multicolumn{3}{|c|}{ Prestress Loss (\%) } & \multirow{2}{*}{$\frac{\sigma_{l 1}}{\sigma_{l 1}+\sigma_{l 2}}(\%)$} \\
\hline & & $\sigma_{l 1}$ & $\sigma_{l 2}$ & $\sigma_{l 1}+\sigma_{l 2}$ & \\
\hline 20 & 8771 & 4.3 & 3.4 & 7.8 & 55.6 \\
\hline 25 & 7099 & 5.3 & 2.8 & 8.1 & 65.6 \\
\hline 30 & 6000 & 6.3 & 2.4 & 8.7 & 72.7 \\
\hline 35 & 5230 & 7.2 & 2.1 & 9.3 & 77.8 \\
\hline 40 & 4667 & 8.1 & 1.8 & 10.0 & 81.4 \\
\hline 45 & 4243 & 8.9 & 1.7 & 10.6 & 84.1 \\
\hline
\end{tabular}

Table 3. Theoretical prestress loss of BFRP tendons given the slab width of $4.5 \mathrm{~m}$.

\begin{tabular}{|c|c|c|c|c|c|}
\hline \multirow{2}{*}{ Distribution Angle $\left({ }^{\circ}\right)$} & \multirow{2}{*}{ Length of BFRP Tendon (mm) } & \multicolumn{3}{|c|}{ Prestress Loss (\%) } & \multirow{2}{*}{$\frac{\sigma_{l 1}}{\sigma_{l 1}+\sigma_{l 2}}(\%)$} \\
\hline & & $\sigma_{l 1}$ & $\sigma_{l 2}$ & $\sigma_{l 1}+\sigma_{l 2}$ & \\
\hline 20 & 13,157 & 2.9 & 5.1 & 8.0 & 36.0 \\
\hline 25 & 10,648 & 3.6 & 4.2 & 7.7 & 46.0 \\
\hline 30 & 9000 & 4.2 & 3.5 & 7.7 & 54.3 \\
\hline 35 & 7846 & 4.8 & 3.1 & 7.9 & 61.0 \\
\hline 40 & 7001 & 5.4 & 2.8 & 8.2 & 66.2 \\
\hline 45 & 6364 & 6.0 & 2.5 & 8.5 & 70.3 \\
\hline
\end{tabular}

Table 4. Theoretical prestress loss of BFRP tendons given the slab width of $9.0 \mathrm{~m}$.

\begin{tabular}{cccccc}
\hline \multirow{2}{*}{ Distribution Angle $\left(^{\circ}\right)$} & Length of BFRP Tendon $(\mathbf{m m})$ & \multicolumn{3}{c}{ Prestress Loss $(\%)$} & \multirow{2}{*}{$\frac{\sigma_{l 1}}{\sigma_{l 1}+\sigma_{l 2}}(\%)$} \\
\cline { 3 - 5 } & & $\sigma_{l 1}$ & $\sigma_{l 2}$ & $\sigma_{l 1}+\sigma_{l 2}$ & \\
\hline 20 & 26,314 & 1.4 & 10.0 & 11.4 & 12.6 \\
30 & 21,296 & 1.8 & 8.2 & 9.9 & 17.9 \\
35 & 18,000 & 2.1 & 6.9 & 9.1 & 23.2 \\
40 & 15,691 & 2.4 & 6.1 & 8.5 & 28.4 \\
45 & 14,002 & 2.7 & 5.4 & 8.2 & 33.2 \\
& 12,728 & 3.0 & 5.0 & 7.9 & 37.5 \\
\hline
\end{tabular}


Table 5. Theoretical prestress loss of BFRP tendons given the slab width of $12.75 \mathrm{~m}$.

\begin{tabular}{cccccc}
\hline \multirow{2}{*}{ Distribution Angle $\left({ }^{\circ}\right)$} & Length of BFRP Tendon (mm) & \multicolumn{3}{c}{ Prestress Loss (\%) } & \multicolumn{2}{c}{$\sigma_{l 1}$} \\
\cline { 3 - 5 } & & $\sigma_{l 1}$ & $\sigma_{l 2}$ & $\sigma_{l 1}+\sigma_{l 2}$ & \\
\hline 20 & 37,279 & 1.0 & 13.9 & 14.9 & 6.8 \\
25 & 30,169 & 1.3 & 11.4 & 12.6 & 9.9 \\
30 & 25,500 & 1.5 & 9.7 & 11.2 & 13.3 \\
35 & 22,229 & 1.7 & 8.5 & 10.2 & 16.7 \\
40 & 19,835 & 1.9 & 7.6 & 9.5 & 20.0 \\
45 & 18,031 & 2.1 & 7.0 & 9.1 & 23.2 \\
\hline
\end{tabular}

As described in Table 2, the theoretical prestress loss of BFRP tendons in the prestressing stage was between $7.8 \%$ and $10.6 \%$, given the slab width of $3.0 \mathrm{~m}$. The greater the distribution angle of the BFRP tendon, the higher the $\sigma_{11}$ and the lower the $\sigma_{12}$. When the distribution angle increased from $20^{\circ}$ to $45^{\circ}, \sigma_{11}$ rose from $4.3 \%$ to $8.9 \%$ while $\sigma_{12}$ reduced from $3.4 \%$ to $1.7 \%$, and therefore the proportion of $\sigma_{11}$ in the total prestress loss in the prestressing stage increased from $55.6 \%$ to $84.1 \%$, implying that the main prestress loss of BFRP tendons in the prestressing stage given a $3.0 \mathrm{~m}$ wide slab was caused by anchorage deformation and prestress retraction $\left(\sigma_{11}\right)$.

It can be illustrated from Table 3 that the total prestress loss of the BFRP tendon in the prestressing stage was between $7.7 \%$ to $8.5 \%$, given a $4.5 \mathrm{~m}$ wide prestressed concrete slab. With the increase of the distribution angle of the BFRP tendon, $\sigma_{11}$ increased from $2.9 \%$ to $6.0 \%$ while $\sigma_{12}$ experienced a drop of $2.6 \%$, and the proportion of $\sigma_{11}$ in the prestress loss in the prestressing stage increased from $36.0 \%$ to $70.3 \%$, demonstrating that the main prestress loss was caused by the friction between the BFRP tendon and the surrounding casing pipe $\left(\sigma_{12}\right)$ with the distribution angle less than $30^{\circ}$. However, when the distribution angle was higher than $30^{\circ}$, the main loss resulted from anchorage deformation and prestress retraction $\left(\sigma_{11}\right)$.

For a $9.0 \mathrm{~m}$ wide slab, the prestress loss in the prestressing stage decreased from $11.4 \%$ to $7.9 \%$ when the distribution angle of the BFRP tendon varied from $20^{\circ}$ to $45^{\circ}$ given a $1.6 \%$ increase in $\sigma_{11}$ and a $5.0 \%$ decrease in $\sigma_{12}$. It is shown in Table 4 that the main prestress loss was caused by the friction between the BFRP tendon and the surrounding casing pipe $\left(\sigma_{12}\right)$, since the proportion of $\sigma_{11}$ was always less than $38 \%$, regardless of the distribution angle.

Similar to the results for the slab width of $9.0 \mathrm{~m}$, the main prestress loss given the slab width of $12.75 \mathrm{~m}$ was caused by the friction between the BFRP tendon and the surrounding casing pipe $\left(\sigma_{12}\right)$, as shown in Table 5. The total prestress loss varied from $9.1 \%$ to $14.9 \%$, with the variation of the distribution angle being between $20^{\circ}$ and $45^{\circ}$.

In general, the prestress loss in the prestressing stage ( $\sigma_{11}$ and $\left.\sigma_{12}\right)$ varied with the distribution angle of the BFRP tendon and the slab width. Given the same slab width, $\sigma_{11}$ increased and $\sigma_{12}$ decreased when the distribution angle varied from $20^{\circ}$ and $45^{\circ}$, and the proportion of $\sigma_{11}$ in the total prestress loss in the prestressing stage rose as well. However, given the same distribution angle, the $\sigma_{11}$ decreased while $\sigma_{12}$ significantly increased with the increase in slab width, and the proportion of $\sigma_{11}$ went down gradually.

\subsubsection{Prestress Loss during the In-Service Stage}

It can be found from Equations (3)-(6) that the length of the prestressed tendon had no impact on the prestress loss during the in-service stage, and as a result, the prestress loss did not vary with the change of the slab width. Given the same properties of prestressed tendon and concrete, the prestress loss during the in-service stage was a fixed value. The prestress loss of the BFRP tendon during the in-service stage is summarized in Table 6. It can be found that the total prestress loss during the in-service stage $(5.2 \%)$ was much smaller than that in the prestressing stage. 
Table 6. Theoretical prestress loss of BFRP tendons during the in-service stage.

\begin{tabular}{ccc}
\hline$\sigma_{14}(\%)$ & $\sigma_{15}(\%)$ & $\sigma_{14}+\sigma_{15}(\%)$ \\
\hline 3.2 & 2.0 & 5.2 \\
\hline
\end{tabular}

\subsubsection{Total Prestress Loss of BRRP Tendons}

The total prestress loss of BFRP tendons at various distribution angles and slab widths is summarized in Table 7. The smallest prestress loss of the BFRP tendons was 12.9\%, given the slab width of $3.0 \mathrm{~m}$ and distribution angle of $20^{\circ}$, while the highest prestress loss was $20.1 \%$, given the slab width of $12.75 \mathrm{~m}$ and distribution angle of $20^{\circ}$. For the slab width of $9.0 \mathrm{~m}$ and $12.75 \mathrm{~m}$, the prestress loss decreased with the rise of the distribution angle, while for the slab width of $4.5 \mathrm{~m}$, the prestress loss decreased first and then increased with the minimum loss of $12.9 \%$ when the distribution angle was $30^{\circ}$. In the case of a $3.0 \mathrm{~m}$ wide slab, the prestress loss experienced a continuous increase with the rise of the distribution angle.

Table 7. The total prestress loss of BFRP tendons.

\begin{tabular}{ccccc}
\hline \multirow{2}{*}{ Distribution Angle $\left(^{\circ}\right.$ ) } & \multicolumn{4}{c}{ Total Prestress Loss (\%) } \\
\cline { 2 - 5 } & Slab Width $=\mathbf{3 . 0} \mathbf{~ m}$ & Slab Width $=\mathbf{4 . 5}$ & Slab Width $=\mathbf{9 . 0} \mathbf{~ m}$ & Slab Width $=\mathbf{1 2 . 7 5} \mathbf{~ m}$ \\
\hline 20 & 12.9 & 13.2 & 16.6 & 20.1 \\
25 & 13.3 & 12.9 & 15.1 & 17.8 \\
30 & 13.9 & 12.9 & 14.2 & 15.4 \\
35 & 14.5 & 13.1 & 13.7 & 14.7 \\
40 & 15.1 & 13.4 & 13.3 & 14.2 \\
45 & 15.8 & 13.6 & 13.1 & \\
\hline
\end{tabular}

As expected, given the same distribution angle, the total prestress loss varied with the slab width as well. With a distribution angle of $20^{\circ}$, the greater the slab width, the higher the total prestress loss. However, when the distribution angle was more than $20^{\circ}$, the prestress loss experienced a decrease first and then increased with the increase in slab width, given the fact that the higher the distribution angle of the BFRP tendon, the faster the prestress loss decreased.

\section{Comparison of the Prestress Loss with Steel Strands}

\subsection{Calculation Process of the Prestress Loss for Steel Strands}

\subsubsection{Prestress Loss Due to Anchorage Deformation and Prestress Retraction}

For the prestress loss caused by anchorage deformation and prestress retraction, the calculation process is the same as that for BFRP tendons, as shown in Equation (1).

\subsubsection{Prestress Loss from the Friction between Steel Strands and the Surrounding Casing Pipe}

Similar to BFRP tendons, friction occurs between the steel strand and the casing pipe during the stretching process of the prestressed steel strand. The calculation method is defined in Equation (8).

$$
\sigma_{l 2}= \begin{cases}\sigma_{\operatorname{con}}\left(1-\frac{1}{e^{\kappa x+\mu \theta}}\right) & \kappa x+\mu \theta>0.3 \\ \sigma_{\operatorname{con}}(\kappa x+\mu \theta) & \kappa x+\mu \theta \leq 0.3\end{cases}
$$

On the basis of the Chinese standard JGJ 92-2016 [25], the value of $\kappa$ and $\mu$ can be assumed to be 0.004 and 0.09 , respectively, given the nominal diameter of the steel strand being $9.5 \mathrm{~mm}, 12.7 \mathrm{~mm}$, $15.2 \mathrm{~mm}$, and $15.7 \mathrm{~mm}$. 


\subsubsection{Prestress Loss Due to Elastic Compression of Concrete}

Like the case of BFRP tendons, the prestress loss caused by elastic compression of concrete can be neglected given the application of the hypertension in cross-tensioned concrete pavements.

\subsubsection{Prestress Loss from the Relaxation of Prestressed Steel Strands}

For steel strands, the prestress loss caused by relaxation of prestress tendons can be determined on the basis of the relationship between the tension control stress $\sigma_{\text {con }}$ and the standard tensile strength $f_{\mathrm{ptk}}$ of the prestressed steel strands, as presented in Equation (9). Normally, the tension control stress is around $75 \%$ of the standard tensile strength.

$$
\sigma_{l 4}=\left\{\begin{array}{cc}
0.20\left(\frac{\sigma_{\mathrm{con}}}{f_{\mathrm{ptk}}}-0.575\right) \sigma_{\mathrm{con}} & 0.7 f_{\mathrm{ptk}}<\sigma_{\mathrm{con}} \leq 0.8 f_{\mathrm{ptk}} \\
0.125\left(\frac{\sigma_{\mathrm{con}}}{f_{\mathrm{ptk}}}-0.5\right) \sigma_{\mathrm{con}} & 0.5 f_{\mathrm{ptk}}<\sigma_{\mathrm{con}} \leq 0.7 f_{\mathrm{ptk}} \\
0 & \sigma_{\mathrm{con}} \leq 0.5 f_{\mathrm{ptk}}
\end{array}\right.
$$

\subsubsection{Prestress Loss Due to Shrinkage and Creep of Concrete}

For steel strands, the prestress loss resulted from the concrete shrinkage and concrete creep can be obtained through Equation (10).

$$
\sigma_{l 5}=\frac{55+300 \frac{\sigma_{\mathrm{pc}}}{f^{\prime} \mathrm{cu}}}{1+15 \rho}
$$

According to Equations (1) and (8)-(10), the total prestress loss for steel strands can be obtained.

\subsection{Results for Steel Strands}

The same input parameters for concrete slabs and distribution angles of BFRP tendons were used in the calculation of prestress loss for steel strands. The diameter of the steel strands was assumed to be $15.2 \mathrm{~mm}$ with the nominal cross-sectional area being $184 \mathrm{~mm}^{2}$, and the ultimate tensile strength and elastic modulus of steel strands were $1860 \mathrm{MPa}$ and $195 \mathrm{GPa}$, respectively. The tension control stress of steel strands was $75 \%$ of the ultimate tensile strength, namely, $1395 \mathrm{MPa}$ in this case. Given the distribution angle of $30^{\circ}$ and spacing of $1000 \mathrm{~mm}$, the mean longitudinal compressive stress for steel strands was calculated to be $3.85 \mathrm{MPa}$ with Equation (7), and therefore the corresponding spacing of steel strands at each distribution angle $\left(20^{\circ}, 25^{\circ}, 30^{\circ}, 35^{\circ}, 40^{\circ}\right.$, and $\left.45^{\circ}\right)$ were $1721 \mathrm{~mm}, 1296 \mathrm{~mm}$, $1000 \mathrm{~mm}, 780 \mathrm{~mm}, 609 \mathrm{~mm}$, and $471 \mathrm{~mm}$, respectively.

\subsubsection{Prestress Loss in the Prestressing Stage}

With Equations (1) and (8), the prestress loss of steel strands in the prestressing stage at different distribution angles $\left(20^{\circ}, 25^{\circ}, 30^{\circ}, 35^{\circ}, 40^{\circ}\right.$, and $\left.45^{\circ}\right)$ can be obtained given the slab width of $3.0 \mathrm{~m}, 4.5 \mathrm{~m}$, $9.0 \mathrm{~m}$, and $12.75 \mathrm{~m}$, as presented in Tables $8-11$, respectively. 
Table 8. Theoretical prestress loss of steel strands given the slab width of $3.0 \mathrm{~m}$.

\begin{tabular}{|c|c|c|c|c|c|}
\hline \multirow{2}{*}{ Distribution Angle $\left({ }^{\circ}\right)$} & \multirow{2}{*}{ Length of Steel Strand (mm) } & \multicolumn{3}{|c|}{ Prestress Loss (\%) } & \multirow{2}{*}{$\frac{\sigma_{l 1}}{\sigma_{l 1}+\sigma_{l 2}}(\%)$} \\
\hline & & $\sigma_{l 1}$ & $\sigma_{l 2}$ & $\sigma_{l 1}+\sigma_{l 2}$ & \\
\hline 20 & 8771 & 9.6 & 3.4 & 13.0 & 73.5 \\
\hline 25 & 7099 & 11.8 & 2.8 & 14.6 & 80.8 \\
\hline 30 & 6000 & 14.0 & 2.4 & 16.3 & 85.5 \\
\hline 35 & 5230 & 16.0 & 2.1 & 18.1 & 88.6 \\
\hline 40 & 4667 & 18.0 & 1.8 & 19.8 & 90.7 \\
\hline 45 & 4243 & 19.8 & 1.7 & 21.5 & 92.2 \\
\hline
\end{tabular}

Table 9. Theoretical prestress loss of steel strands given the slab width of $4.5 \mathrm{~m}$.

\begin{tabular}{|c|c|c|c|c|c|}
\hline \multirow{2}{*}{ Distribution Angle ( ${ }^{\circ}$ ) } & \multirow{2}{*}{ Length of Steel Strand (mm) } & \multicolumn{3}{|c|}{ Prestress Loss (\%) } & \multirow{2}{*}{$\frac{\sigma_{l 1}}{\sigma_{l 1}+\sigma_{l 2}}(\%)$} \\
\hline & & $\sigma_{l 1}$ & $\sigma_{l 2}$ & $\sigma_{l 1}+\sigma_{l 2}$ & \\
\hline 20 & 13,157 & 6.4 & 5.1 & 11.5 & 55.4 \\
\hline 25 & 10,648 & 7.9 & 4.2 & 12.0 & 65.4 \\
\hline 30 & 9000 & 9.3 & 3.5 & 12.9 & 72.5 \\
\hline 35 & 7846 & 10.7 & 3.1 & 13.8 & 77.6 \\
\hline 40 & 7001 & 12.0 & 2.8 & 14.7 & 81.3 \\
\hline 45 & 6364 & 13.2 & 2.5 & 15.7 & 84.0 \\
\hline
\end{tabular}

Table 10. Theoretical prestress loss of steel strands given the slab width of $9.0 \mathrm{~m}$.

\begin{tabular}{cccccc}
\hline \multirow{2}{*}{ Distribution Angle $\mathbf{(}^{\circ}$ ) } & Length of Steel Strand $(\mathbf{m m})$ & \multicolumn{3}{c}{ Prestress Loss $(\mathbf{\%})$} & \multirow{2}{*}{$\sigma_{l 1}$} \\
\cline { 3 - 5 } & & $\sigma_{l 1}$ & $\sigma_{l 2}$ & $\sigma_{l 1}+\sigma_{l 2}$ & \\
\hline 20 & 26,314 & 3.2 & 10.0 & 13.2 & 24.2 \\
25 & 21,296 & 3.9 & 8.2 & 12.1 & 32.5 \\
30 & 18,000 & 4.7 & 6.9 & 11.6 & 40.1 \\
35 & 15,691 & 5.3 & 6.1 & 11.4 & 46.8 \\
40 & 14,002 & 6.0 & 5.4 & 11.4 & 52.4 \\
45 & 12,728 & 6.6 & 5.0 & 11.6 & 57.0 \\
\hline
\end{tabular}

Table 11. Theoretical prestress loss of steel strands given the slab width of $12.75 \mathrm{~m}$.

\begin{tabular}{cccccc}
\hline \multirow{2}{*}{ Distribution Angle ( ${ }^{\circ}$ ) } & Length of Steel Strand (mm) & \multicolumn{3}{c}{ Prestress Loss (\%) } & \multicolumn{2}{c}{$\sigma_{l 1}$} \\
\cline { 3 - 5 } & & $\sigma_{l 1}$ & $\sigma_{l 2}$ & $\sigma_{l 1}+\sigma_{l 2}$ & \\
\hline 20 & 37,279 & 2.2 & 13.9 & 16.1 & 14.0 \\
25 & 30,169 & 2.8 & 11.4 & 14.1 & 19.6 \\
30 & 25,500 & 3.3 & 9.7 & 13.0 & 25.3 \\
35 & 22,229 & 3.8 & 8.5 & 12.3 & 30.7 \\
40 & 19,835 & 4.2 & 7.6 & 11.9 & 35.7 \\
45 & 18,031 & 4.7 & 7.0 & 11.6 & 40.1 \\
\hline
\end{tabular}

It can be illustrated from Tables 8-11 that the prestress loss in the prestressing stage ranged from 11.5 to $21.5 \%$. The main prestress loss was caused by anchorage deformation and prestress retraction $\left(\sigma_{11}\right)$ when the slab width was less than $9.0 \mathrm{~m}$, and by the friction between the steel strand and the surrounding casing pipe $\left(\sigma_{12}\right)$ when the slab width was higher than $9.0 \mathrm{~m}$.

In general, the relationship between the prestress loss $\left(\sigma_{11}\right.$ and $\left.\sigma_{12}\right)$ and the distribution angle of steel strands with the same slab width was similar to the results of BFRP tendons, given the greater the distribution angle, the higher the $\sigma_{11}$ and the lower the $\sigma_{12}$, resulting in the higher proportion of $\sigma_{11}$ in the prestress loss in the prestressing stage. Conversely, given the same distribution angle, $\sigma_{11}$ decreased and $\sigma_{12}$ increased with the increase of the slab width, causing a drop in the proportion of $\sigma_{11}$ in the prestress loss in the prestressing stage. 


\subsubsection{Prestress Loss during the In-Service Stage}

Similar to BFRP tendons, the prestress loss of steel strands during the in-service stage did not vary with the slab width and distribution angle of steel strands either. The prestress loss of steel strands during the in-service stage is listed in Table 12. The prestress loss caused by concrete shrinkage and creep $\left(\sigma_{15}\right)$ was $6.9 \%$, almost twice of that caused due to the relaxation of the prestressed steel strands $\left(\sigma_{14}\right)$. As expected, the prestress loss of steel strands during the in-service stage was significantly lower than that in the prestressing stage.

Table 12. Theoretical prestress loss of steel strands during the in-service stage.

\begin{tabular}{ccc}
\hline$\sigma_{14}(\%)$ & $\sigma_{15}(\%)$ & $\sigma_{14}+\sigma_{15}(\%)$ \\
\hline 3.5 & 6.9 & 10.4 \\
\hline
\end{tabular}

\subsubsection{Total Prestress Loss of Steel Strands}

The total prestress loss of steel strands at different distribution angles and slab widths is summarized in Table 13.

Table 13. The total prestress loss of steel strands (\%).

\begin{tabular}{ccccc}
\hline \multirow{2}{*}{ Distribution Angle $\left(^{\circ}\right.$ ) } & \multicolumn{4}{c}{ Total Prestress Loss (\%) } \\
\cline { 2 - 5 } & Slab Width $=\mathbf{3 . 0} \mathbf{~ m}$ & Slab Width $\mathbf{=} \mathbf{4 . 5} \mathbf{~}$ & Slab Width $=\mathbf{9 . 0} \mathbf{~ m}$ & Slab Width $=\mathbf{1 2 . 7 5} \mathbf{~ m}$ \\
\hline 20 & 30.8 & 21.9 & 23.6 & 26.5 \\
25 & 25.0 & 22.4 & 22.5 & 23.5 \\
30 & 26.7 & 23.2 & 22.0 & 22.7 \\
35 & 28.5 & 24.2 & 21.8 & 22.2 \\
40 & 30.2 & 25.1 & 21.8 & 22.0 \\
45 & 31.8 & 26.1 & 21.9 & \\
\hline
\end{tabular}

As shown in Table 13, given the slab width ranging from $3.0 \mathrm{~m}$ to $12.75 \mathrm{~m}$ and the distribution angle from $20^{\circ}$ to $45^{\circ}$, the total prestress loss of steel strands was from $21.8 \%$ to $31.8 \%$, with the lowest and the highest prestress loss being $21.8 \%$ and $31.8 \%$, respectively. For a given distribution angle of steel strands, the total prestress loss reduced first, and then underwent a small increase as the slab width increased. The smaller the distribution angle, the greater the decrease rate.

\subsection{Comparison of BFRP Tendons and Steel Strands}

\subsubsection{Prestress Loss in the Prestressing Stage}

The prestress loss of BFRP tendons and steel strands in the prestressing stage at various distribution angles and with different slab widths is presented in Figure 1. Whether it was BFPR tendon or steel strand, the prestress loss arising from anchorage deformation and prestress retraction $\left(\sigma_{11}\right)$ decreased as the slab width increased, and increased as the distribution angle increased, as shown in Figure 1a, signifying that the type of the prestressed tendon had limited impact on the relationship between the prestress loss $\sigma_{11}$ and the slab width and distribution angle. For the prestress loss resulting from the friction between the prestressed tendon and the surrounding casing pipe $\left(\sigma_{12}\right)$, its values for BFRP tendons and steel strands were the same, given the same slab width and distribution angle, as shown in Figure 1b, demonstrating that the properties of the prestressed reinforcement had no impact on the prestress loss $\sigma_{12}$. 


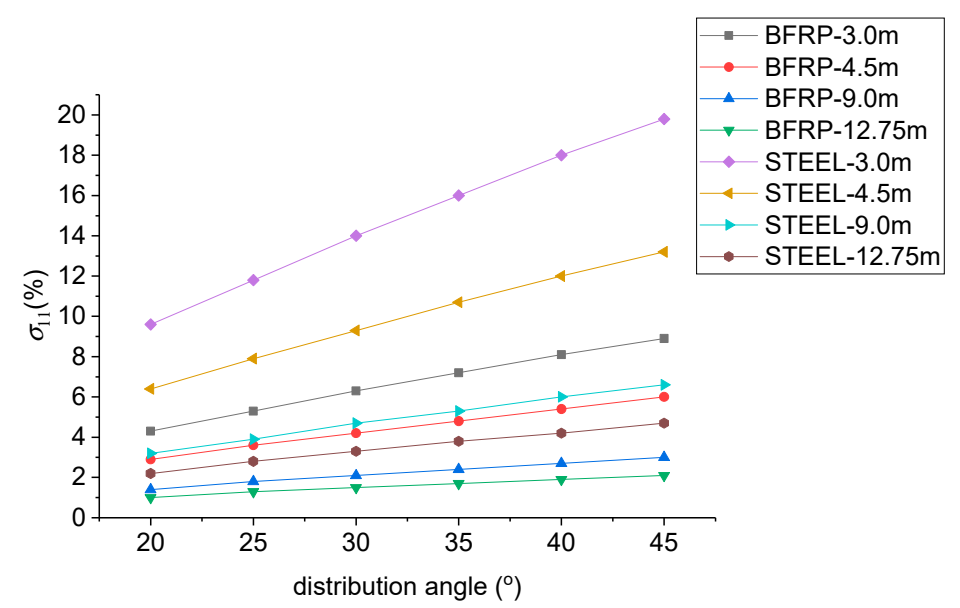

(a) The prestress loss $\sigma_{11}$ of both BFRP tendons and steel strands (\%)

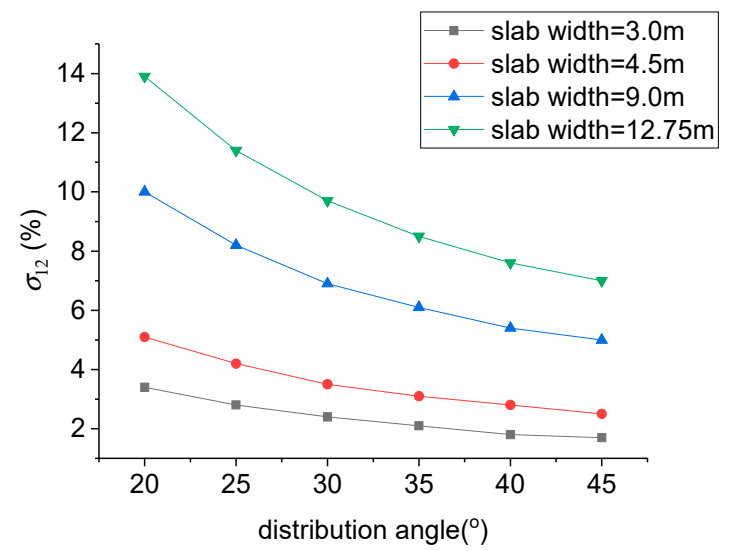

(b) The prestress loss $\sigma_{12}$ of both BFRP tendons and steel strands (\%)

Figure 1. Comparison of prestress loss of BFRP tendons and steel strands in the prestressing stage at various slab widths and distribution angles (\%).

As described in Figure 1, given the same slab width and distribution angle of the prestressed reinforcement, the prestress loss $\sigma_{11}$ of the BFRP tendon was far lower than that of the steel strand, and the difference showed a tremendous increase with the decrease of the slab width and the increase of the distribution angle. When the slab width was $3.0 \mathrm{~m}$ and the distribution angle was $45^{\circ}$, the difference in $\sigma_{11}$ between the BFRP tendon and steel strand reached the maximum value of $10.9 \%$, which illustrated that the use of BFRP tendon can significantly reduce the prestress loss during the prestressing stage, especially with a smaller slab width and a greater distribution angle.

\subsubsection{Prestress Loss during the In-Service Stage}

Figure 2 presents the prestress loss of both BFRP tendons and steel strands during the in-service stage at various slab widths and distribution angles. Similar to the prestress loss in the prestressing stage, the use of BFRP tendons can greatly reduce the prestress loss during the in-service stage given the prestress loss of BFRP tendons and steel strands of $5.2 \%$ and $10.4 \%$, respectively. This was mainly because the application of the BFRP tendon led to a significant decrease in the prestress loss $\sigma_{15}, 4.9 \%$ less than the prestress loss of steel strands. 


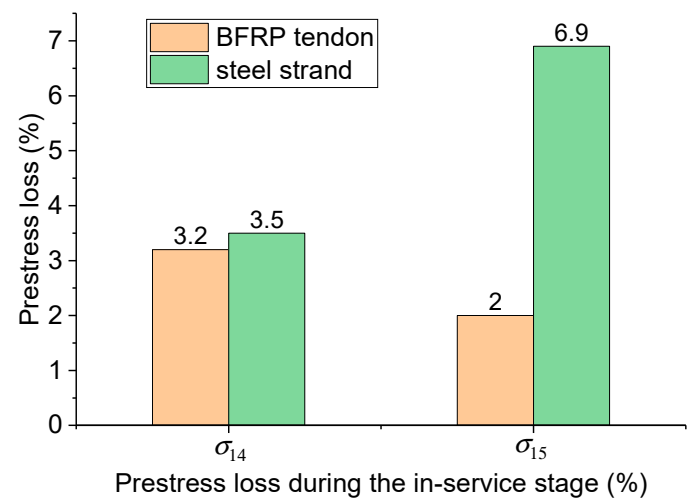

Figure 2. Comparison of prestress loss of BFRP tendons and steel strands during the in-service stage at various slab widths and distribution angles (\%).

\subsubsection{Total Prestress Loss}

As shown in Figure 3, for a specific slab width $(3.0 \mathrm{~m}, 4.5 \mathrm{~m}, 9.0 \mathrm{~m}$, and $12.75 \mathrm{~m})$ and distribution angle $\left(20^{\circ}, 25^{\circ}, 30^{\circ}, 35^{\circ}, 40^{\circ}\right.$, and $\left.45^{\circ}\right)$ of the prestressed tendon, the total prestress loss of the BFRP tendon was always lower than that of the steel strand. The difference between the two prestress losses varied from $6.4 \%$ to $16 \%$ and it decreased with the increase of the slab width. When the slab width was $3.0 \mathrm{~m}$ and the distribution angle was $20^{\circ}$, the difference peaked at $17.9 \%$. When the slab width was $12.75 \mathrm{~m}$ and the distribution angle was $20^{\circ}$, the difference reached the minimum value of $6.4 \%$.

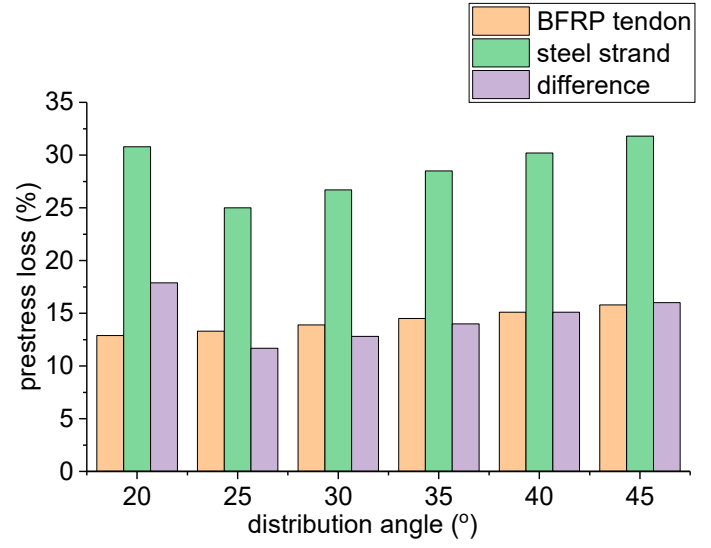

(a) slab width $=3.0 \mathrm{~m}$

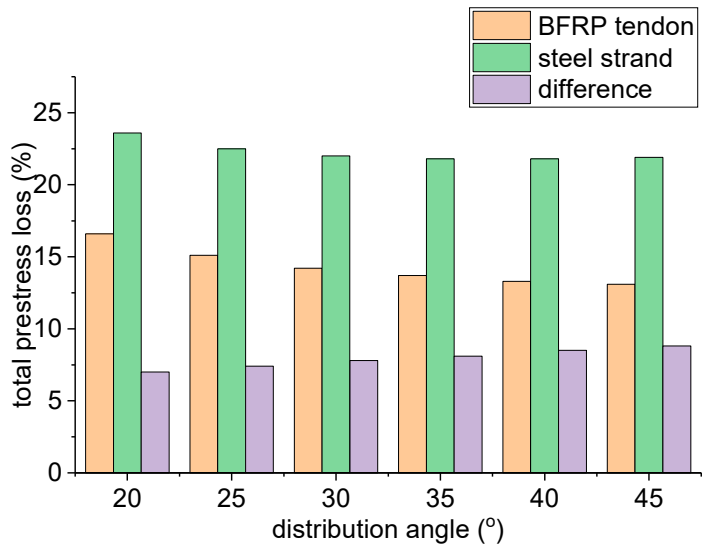

(c) slab width $=9.0 \mathrm{~m}$

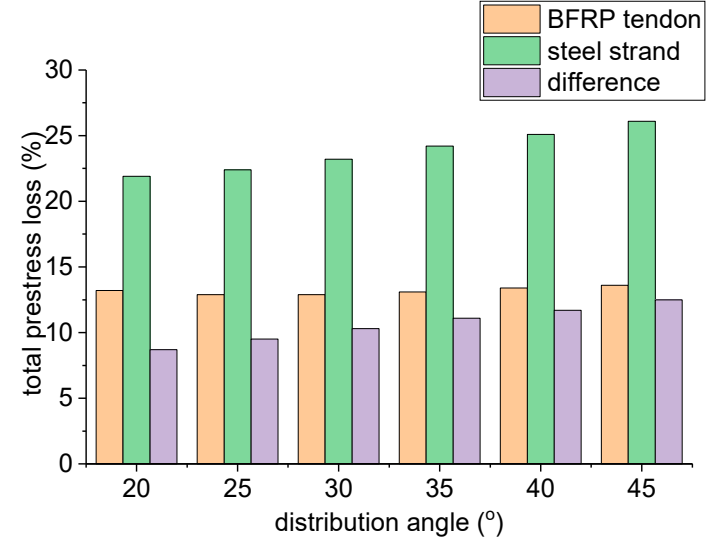

(b) slab width $=4.5 \mathrm{~m}$

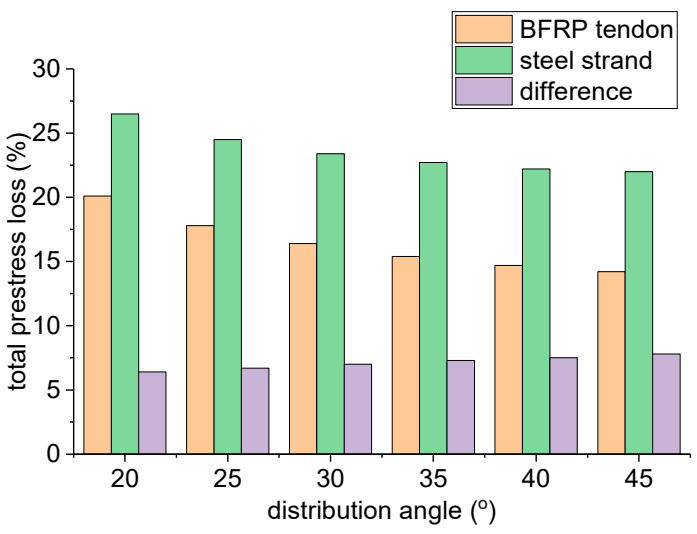

(d) slab width $=12.75 \mathrm{~m}$

Figure 3. Difference in prestress loss between BFRP tendons and steel strands given various slab widths and distribution angles. 
In summary, the use of the BFRP tendon in the cross-tensioned concrete pavement can effectively reduce the prestress loss compared to the steel strand, let alone its corrosion resistance, which can increase the durability of the cross-tensioned concrete pavement. Further lab tests and test sections are still needed for better evaluation of prestress loss of BFRP tendons and the performance of the BFRP-reinforced cross-tensioned concrete pavement.

\section{Conclusions}

This paper proposed a detailed theoretical method and calculation process for determining the prestress loss of the BFRP tendon, a corrosion-resistant and lightweight material, in cross-tensioned concrete pavements with the consideration of the unique relaxation properties of BFRP to improve the durability of the pavement structure. The impact of the slab width and distribution angle of the prestressed tendon on the prestress loss in different stages was studied and compared to the results of traditional steel strands. The conclusions are summarized as follows:

(1) For both BFRP tendons and steel strands, the prestress loss $\sigma_{11}$ decreased and $\sigma_{12}$ increased with the increase of the slab width at a given distribution angle of the prestressed tendon, resulting in a lower proportion of $\sigma_{11}$ in the prestress loss during the prestressing stage. In contrast, given the same slab width, the prestress loss $\sigma_{11}$ increased and $\sigma_{12}$ decreased as distribution angle increased, while the prestress loss was a constant value during the in-service stage.

(2) During the prestressing stage, the prestress loss of BFRP tendons was far lower than that of steel strands, given that the difference of prestress loss $\sigma_{11}$ increased with the decrease of the slab width and the increase of the distribution angle, peaking at $10.9 \%$ when the slab width was $3 \mathrm{~m}$ and the distribution angle was $45^{\circ}$.

(3) During the in-service stage, both the prestress losses of BFRP tendons and steel strands were constant, and the former (5.2\%) was half of the latter (10.4\%).

(4) For a given slab width $(3 \mathrm{~m}, 4.5 \mathrm{~m}, 9.0 \mathrm{~m}$, and $12.75 \mathrm{~m})$ and distribution angle $\left(20^{\circ}, 25^{\circ}, 30^{\circ}, 35^{\circ}\right.$, $40^{\circ}$, and $45^{\circ}$ ), the prestress loss of BFRP tendons was always lower than that of steel strands, with the difference ranging from $6.4 \%$ to $16 \%$. The smaller the slab width, the greater the difference, indicating that BFRP tendons can effectively reduce the prestress loss in concrete pavements, especially when the slab width is smaller.

Author Contributions: Conceptualization: Y.Z.; validation: Z.H. and Y.Z.; investigation: Y.Z.; methodology: Y.Z.; data curation: Y.Z.; supervision: Z.H.; writing—original draft preparation: Y.Z.; writing—review and editing: Y.Z. and Z.H. All authors have read and agreed to the published version of the manuscript.

Funding: This research was funded by Natural Science Foundation of Jiangsu Province (BK20190604); Jiangsu Planned Projects for Postdoctoral Research Funds (2020Z327); Key Laboratory of Road and Traffic Engineering of the Ministry of Education, Tongji University (K202002); and the Fundamental Research Funds for the Central Universities (JUSRP11937).

Acknowledgments: The authors would like to acknowledge the support of Jiaheng Lin and Binghui Gu from Jiangnan University.

Conflicts of Interest: The authors declare no conflict of interest.

\section{References}

1. Tayabji, S.D.; Barenberg, E.J.; Gramling, W.; Teng, P. Prestressed concrete pavement technology update. In Proceedings of the Seventh International Conference on Concrete Pavements, Orlando, FL, USA, 9-13 September 2001.

2. Hossain, M.; Hancock, J.; Wu, Z. Cross tensioned concrete pavement. J. Transp. Eng. 2003, 129, 427-433. [CrossRef] 
3. Merritt, D.K.; McCullough, B.F.; Burns, N.H. Precast prestressed concrete pavement pilot project near Georgetown, Texas. Transp. Res. Rec. 2003, 1823, 11-17. [CrossRef]

4. Merritt, D.K.; McCullough, B.F.; Burns, N.H. Construction and preliminary monitoring of the Georgetown, Texas precast prestressed concrete pavement. In Research Report 1517-01-1MP, Center for Transportation Research; The University of Texas at Austin: Austin, TX, USA, 2002.

5. Nejad, F.M.; Ghafari, S.; Afandizadeh, S. Numerical analysis of thermal and composite stresses in pre-stressed concrete pavements. Comput. Concr. 2013, 11, 169-182. [CrossRef]

6. Li, N.; Zhang, D.S.; Xv, X.J.; Han, W.W. Numerical simulation on cross tensioned prestressed concrete pavement. In Proceedings of the Fourth International Conference on Transportation Engineering, Chengdu, China, 19-20 October 2013.

7. Qu, B.; Weng, X.; Zhang, J.; Mei, J.; Guo, T.; Li, R.; An, S. Analysis on the deflection and load transfer capacity of a prefabricated airport prestressed concrete pavement. Constr. Build. Mater. 2017, 157, 449-458. [CrossRef]

8. Naddafi, M.F.; Sadeghi, V. Finite element investigation of the prestressed jointed concrete pavements. J. Fundam. Appl. Sci. 2016, 8, 167-178. [CrossRef]

9. Kim, K.; Tia, M.; Greene, J. Evaluation of structural behavior of precast prestressed concrete pavement with finite element analysis. Transp. Res. Rec. 2016, 2590, 84-93. [CrossRef]

10. Han, S.; Chen, D.; Ling, C.; Zhang, D.S. Study on sliding layer of cross-tensioned concrete pavement. Road Mater. Pavement Des. 2015, 16, 518-535. [CrossRef]

11. Cable, N.D.; McCullough, B.F.; Burns, N.H. New concepts in prestressed concrete pavement. In Research Report 401-2. Center for Transportation Research; The University of Texas at Austin: Austin, TX, USA, 1985.

12. Zhang, D.S.; Xv, X.J.; Li, N.; Han, W.W. Research on the design method of diagonal post-tensioned prestressed jointless cement concrete pavement. In Proceedings of the Eleventh International Conference of Chinese Transportation Professionals, Nanjing, China, 14-17 August 2011.

13. Au, F.T.K.; Si, X.T. Accurate time-dependent analysis of concrete bridges considering concrete creep, concrete shrinkage and cable relaxation. Eng. Struct. 2011, 33, 118-126. [CrossRef]

14. Kim, S.H.; Park, S.Y.; Park, Y.; Jeon, S.J. Friction characteristics of post-tensioning tendons in full-scale structures. Eng. Struct. 2019, 183, 389-397. [CrossRef]

15. Yang, M.F.; Gong, J.X.; Yang, X.Y. Refined calculation of time-dependent prestress losses in prestressed concrete girders. Struct. Infrastruct. Eng. 2020, 16, 1430-1446. [CrossRef]

16. Jeon, C.H.; Nguyen, C.D.; Shim, C.S. Assessment of mechanical properties of corroded prestressing strands. Appl. Sci. 2020, 10, 4055. [CrossRef]

17. Carsana, M.; Bertolini, L. Corrosion failure of post-tensioning tendons in alkaline and chloride-free segregated grout: A case study. Struct. Infrastruct. Eng. 2015, 11, 402-411. [CrossRef]

18. Ahmed, A.; Guo, S.C.; Zhang, Z.H.; Shi, C.J.; Zhu, D.J. A review on durability of fiber reinforced polymer (FRP) bars reinforced seawater sea sand concrete. Constr. Build. Mater. 2020, 256, 119484. [CrossRef]

19. Gu, X.Y.; Dong, Q. Laboratory test and numerical simulation of bond performance between baslat fiber reinforced polymer rebar and concrete. J. Test. Eval. 2012, 40, 1148-1155. [CrossRef]

20. Shen, D.J.; Wen, C.Y.; Zhu, P.F.; Li, M.; Ojha, B.; Li, C.C. Bond behavior between basalt fiber-reinforced polymer bars and concrete under cyclic loading. Constr. Build. Mater. 2020, 258, 119518. [CrossRef]

21. Technical Code for Engineerings of Prestressed Concrete Pavement; GB 50422-2017; Ministry of Housing and Urban-Rural Development of China: Beijing, China, 2017.

22. Yu, L.; Yang, X.; Yan, X.H.; Zhang, X.W.; Zhao, T.; Duan, C.; Mills-Beale, J. Design and construction of oblique prestressed concrete pavement: A case study in China. Appl. Sci. 2018, 8, 607. [CrossRef]

23. Wang, X.; Shi, J.Z.; Liu, J.X.; Yang, L.; Wu, Z.S. Creep behavior of basalt fiber reinforced polymer tendons for prestressing application. Mater. Des. 2014, 59, 558-564. [CrossRef]

24. Shi, J.Z.; Wang, X.; Huang, H.; Wu, Z.S. Relaxation behavior of prestressing basalt fiber-reinforced polymer tendons considering anchorage slippage. J. Compos. Mater. 2017, 51, 1275-1284. [CrossRef]

25. Technical Specification for Concrete Structures Prestressed with Unbonded Tendons; JGJ 92-2016; Ministry of Housing and Urban-Rural Development of China: Beijing, China, 2016. 
26. Motwani, P.; Perogamvros, N.; Taylor, S.; Laskar, A. Performance of industrial wedge-anchors for pre-stressing BFRP bars: Experimental and numerical studies. Compos. Struct. 2020, 251, 112592. [CrossRef]

27. Wang, W.W.; Dai, J.G.; Harries, K.A.; Zhang, L. Prediction of prestress losses in RC beams externally strengthened with prestressed CFRP sheets/plates. J. Reinf. Plast. Compos. 2014, 33, 699-713. [CrossRef]

Publisher's Note: MDPI stays neutral with regard to jurisdictional claims in published maps and institutional affiliations.

(C) 2020 by the authors. Licensee MDPI, Basel, Switzerland. This article is an open access article distributed under the terms and conditions of the Creative Commons Attribution (CC BY) license (http://creativecommons.org/licenses/by/4.0/). 